Patricio Espinoza Lucero*

\title{
El derecho fundamental a vivir en un medio ambiente libre de contaminación como derecho social
}

\section{Resumen}

Luego de efectuar un estudio en relación a los derechos sociales, el autor plantea que el derecho a vivir en un medio ambiente libre de contaminación tiene el carácter de tal, singularizado por su carácter colectivo. Luego, conceptualizado de esa forma, lo estudia en relación al principio de igualdad y precisa los deberes que tendría el Estado a fin de garantizarlo.

\section{Palabras clave}

Derechos sociales, derecho a vivir en un medio ambiente libre de contaminación, solidaridad, principio de igualdad, deberes del Estado.

* Abogado, Ayudante Adjunto del Departamento de Derecho Público, Facultad de Derecho, Universidad de Chile

\section{Consideraciones generales respecto a los Derechos Sociales}

El derecho a vivir en un medio ambiente libre de contaminación, en adelante también "DVMLC", consagrado en la Constitución Política de la República, es un derecho fundamental que puede ser clasificado como derecho social, lo que tiene implicancias e impacto en la obligación que le corresponde al Estado para su satisfacción, en la regulación legal del derecho, así como también respecto al tratamiento que recibe por parte de la jurisprudencia.

Se ha definido a los derechos sociales como "derechos a prestaciones públicas positivas"1. Complementando la definición anterior, podemos señalar que para efectos del presente trabajo entenderemos por derechos sociales aquellos que tienen por objetivo resguardar

FERRAJOLI, Luigi, “Derechos y Garantías. La ley del más débil”. Trotta (1999), p.108. 
determinadas situaciones que son de interés de la sociedad en su conjunto, más que resguardar situaciones individuales, como es la principal característica de los Derechos Civiles y Políticos (en adelante "DCP"). La doctrina ha debatido durante las últimas décadas respecto de las diferencias entre los derechos sociales y los DCP, acerca de la exigibilidad de estos últimos en desmedro de los derechos sociales, los cuales vendrían a ser meras normas programáticas que serían exigibles en la medida que los recursos fiscales permitan su realización.

Para sostener la diferencia entre ambos derechos se ha utilizado, en primer lugar, el argumento histórico o de las generaciones de derechos, en virtud del cual, los DCP son derechos de primera generación, mientras que los DESC son derechos de segunda o tercera generación, dependiendo del autor que se siga ${ }^{2}$. En este sentido, por pertenecer a una generación primaria, los DCP tendrían integrada dentro de su estructura jurídica la posibilidad de ser exigibles, puesto que se trata de libertades que el Estado debe reconocer, y que por ende, se traducen en obligaciones inmediatas que los Estados tienen que adoptar para su satisfacción (por ejemplo, el derecho de propiedad, un típico derecho civil y político, debe ser solo protegido por el Estado absteniéndose éste, por ejemplo, de desposeer a los propietarios de sus bienes).

Otro de los argumentos que se suelen señalar para establecer la diferencia entre los DCP y los derechos sociales radica en la imposibilidad de los Estados de cumplir con las promesas normativas que contienen los derechos sociales, puesto que su implementación les demanda muchos recursos. Los países en desarrollo normalmente no contarán con los recursos necesarios para la satisfacción de estos derechos, así por ejemplo, respecto al derecho a la educación, va a ser muy caro para los Estados contar con escuelas y en general infraestructura pública de primera calidad para satisfacer este derecho; o en el caso del derecho a la salud, los Estados no tendrán los recursos para financiar todo el personal médico que se requiere para una adecuada atención de las personas. Por el contrario, los DCP no requerirían de mayores recursos para su realización, por ejemplo al Estado le cuesta cero el abstenerse de afectar la libertad de expresión.

En el mismo orden de cosas, se señala que los DESC son de aplicación progresiva, es decir, en el tiempo y a medida que los Estados cuenten con los recursos necesarios podrán ser éstos satisfechos, mientras que por el contrario los DCP son de aplicación inmediata, pues no requieren de la acción positiva del Estado, sino que más bien de abstenciones. $^{3}$

\footnotetext{
Para Trindade, los DCP corresponderían a una primera generación a partir de 1948 y la Declaración Universal de Derechos Humanos, mientras que el desarrollo de los DESC se produce a partir de 1966 con el PIDESC. Cançado, Antonio A., "El derecho internacional de los derechos humanos en el siglo XXI", Santiago, Editorial Jurídica de Chile, 2006, pp. 95-99. Por su parte, el profesor Gregorio Peces Barba señala que estos derechos son de tercera generación, siendo los de primera generación los denominados derechos individuales, luego los derechos civiles y políticos, para finalmente estar los derechos económicos, sociales y culturales. PECES-BARBA, Gregorio, "Los Derechos Económicos, Sociales y Culturales: su génesis y concepto", Revista Derechos y Libertades No. 6. Instituto de Derechos Humanos Bartolomé de las Casas. Universidad Carlos III de Madrid. BOE. Febrero, 1998. pp. 26-30.

3 Cançado, Antonio A., op. cit. p. 96.
} 
Me sumo a aquellas posturas que no ven mayores diferencias entre los DESC y los DCP, pues ambos derechos comparten unas mismas características. De este modo, por ejemplo, no es efectivo que los DCP sean derechos que no le cuestan dinero al Estado, puesto que éste destina enormes recursos del presupuesto público para mantener un sistema judicial destinado, en su gran mayoría, a la protección del derecho de propiedad. ${ }^{4}$ Por otra parte, la satisfacción de los DESC considera obligaciones inmediatas o acciones positivas por parte del Estado, tales como el derecho de huelga o la libertad sindical'5.

En adición a lo señalado anteriormente, no es posible hoy seguir haciendo esta distinción, que resulta inoficiosa pues ambas categorías de derechos comparten las mismas características. El principal argumento que se ha señalado a este respecto es la circunstancia de que uno de los mayores gastos en que incurre el Estado es el mantenimiento de un costoso aparato policial y judicial que está destinado en gran parte a la protección del derecho de propiedad, y en general de las libertades. Por otra parte, la línea divisoria entre estas categorías doctrinarias es tan fina que muchas veces se traspasa, de esta forma: "Hay derechos económicos, sociales y culturales entre los derechos de libertad negativa; hay derechos económicos, sociales y culturales como derechos de libertad positiva; hay derechos económicos, sociales y culturales como derechos de participación; hay derechos económicos, sociales y culturales como derechos a prestaciones positivas, pero ni siquiera son mayoría; hay principios rectores de la política social y económica que tienen, naturalmente, contenido económico, social o cultural. Y hay programas de actuación estatal, normas programáticas en sentido puro, con un contenido económico, social o cultural". ${ }^{6}$

Es posible señalar que ambas categorías de derechos tienen como propósito la protección de la persona humana, y en este sentido, es innegable el consenso a nivel global que supone la unidad e indivisibilidad de los derechos económicos y sociales, siendo incluso considerados estos derechos como antecedentes de unos y otros respectivamente. De esta manera, es posible sostener que tradicionales DCP como el derecho a la vida contienen dentro de sí un germen de DESC, por cuanto el derecho a la vida es antecedente de todos los derechos, y porque la protección de la salud no se puede concebir separada del derecho a la vida, misma relación que es posible concebir entre el derecho a la educación y la libertad de expresión ${ }^{7}$.

GARGARELLA, ROBERTO "Primeros Apuntes para una teoría sobre derechos sociales. ¿Es posible justificar un tratamiento juridico diferenciado para los derechos sociales e individuales? Revista Jueces para la democracia, № 31 , 1998, pp. 12-14, disponible en http://dialnet.unirioja.es/servlet/articulo?codigo=174741 [consulta: 13 de julio 2009]

Cançado Trindade, Antonio A., op. cit. p. 100.

GONZÁLEZ, Beatriz, El Estado Social. Naturaleza jurídica y estructura de los derechos sociales. Civitas, 2002, p. 161.

Oficina del Alto Comisionado de las Naciones Unidas para los Derechos Humanos, Los derechos económicos, sociales y culturales. Manual para las instituciones nacionales de derechos humanos, Ginebra, 2004. Disponible en: http://www.ohchr.org/Documents/Publications/training12sp.pdf p. 4. [conculta: 14 de Agosto 2009] 
Es más, recientemente nuestro Tribunal Constitucional en la sentencia Rol $976^{8}$, se ha pronunciado a favor de la tesis de que los derechos sociales son tan derechos como los DCP. Al respecto el fallo seńala que “(...)la amplia mayoría de la doctrina nacional y extranjera reconoce que los derechos sociales, llamados también derechos de prestación o de la segunda generación, son tales y no simples declamaciones o meras expectativas, cuya materialización efectiva quede suspendida hasta que las disponibilidades presupuestarias del Estado puedan llevarlos a la práctica" . Agrega lo siguiente: "[e]l núcleo normativo es que el sujeto tiene un título para exigir que se entreguen ciertos bienes, se le presten ciertos servicios o se le transfieran ciertos recursos. Entre tales derechos encontramos la prestación de un servicio (educación, salud, protección del riesgo, etc.)." ${ }^{10}$ Posteriormente reafirma esta idea señalando: “(...) poner en duda su "practicabilidad" [de los Derechos Sociales] de realización, es una idea confusa, porque esa "reserva de lo posible" Ileva a sostener que la Constitución ha de ser "desactivada", a causa de la imposibilidad económica del Estado de darles satisfacción, convirtiendo así en virtuales las cláusulas fundamentales que aseguran su materialización. ${ }^{11}$

No obstante la circunstancia de la imposibilidad de hacer mayores distinciones entre los derechos sociales y los individuales, en términos de la implementación de éstos sí hay diferencias importantes, puesto que unos y otros no se satisfacen de la misma manera. Por de pronto, y siguiendo con el ejemplo del derecho de propiedad, el que se establezca un derecho que proteja la propiedad no es un antecedente para que el Estado "haga" o "conceda" propiedades a los ciudadanos, puesto que solo aquellos que producto del desarrollo de sus vidas logran convertirse en propietarios, a partir de la relaciones particulares que desarrollan, podrán solicitar la protección de sus propiedades; es decir, quien no es propietario no reclama la protección de la propiedad.

Por el contrario, el caso de los derechos sociales es distinto pues el Estado sí tiene la obligación de proveer los bienes que permitan satisfacer tales derechos, pero con una finalidad concreta, lograr que todas las personas estén en igualdad de condiciones para llevar adelante sus proyectos de vida, para lo cual será necesario "la superación de las desigualdades sociales y el mejoramiento de las condiciones materiales de existencia en amplias capas de la sociedad"12. Así, en el caso de la Educación, el Estado debe poner a disposición de las personas escuelas y liceos en los cuales la población pueda educarse; en el caso de la Salud, el Estado tiene la obligación de disponer de consultorios y hospitales para la atención de la población; y en lo que concierne al DVMLC, el Estado tiene la obligación de generar las condiciones para que el medio ambiente sea el adecuado para el normal desarrollo de la vida.

8 El Recurso fue interpuesto por Silvia Peña Wasaff en el marco de una acción de protección que interpuso la misma recurrente en contra de la Isapre ING (en adelante también la "Isapre") debido a que ésta subió unilateralmente, y a su juicio arbitrariamente, el precio de su plan de salud.

Considerando $26^{\circ}$ del fallo. El destacado es mío.

Ibid. Citando a Jerónimo Betegón, pero haciendo parte integrante de la decisión dicho párrafo.

El destacado es mío.

GONZÁLEZ, Beatriz, op. cit. p. 163. 
Al respecto, el fallo del Tribunal Constitucional anteriormente citado indica que “(...) si bien la doctrina y jurisprudencia comparadas han señalado que los derechos sociales requieren la concretización legal de su contenido, también han realzado que la Constitución establece, en relación con ellos, un núcleo esencial, indisponible por el legislador"13. Agrega el fallo, citando doctrina española, que "[e]xisten derechos de contenido social (...) directamente exigibles. Es el caso, por ejemplo, de la enseñanza básica (...) obligatoria o gratuita. (...) se encuentran derechos de carácter social que formulan estándares mínimos que, desde luego, tienen que ser respetados por leyes y pueden ser directamente invocados". ${ }^{14}$ El DVMLC, y en general la protección constitucional del Medio ambiente tienen como propósito "establecer estándares mínimos que luego tienen que ser respetados por las leyes y que pueden ser directamente invocados".

\section{El Derecho a Vivir en un Medio ambiente Libre de Contaminación en nuestra Constitución: ¿¿stamos en presencia de un verdadero derecho social?}

El inciso $4^{\circ}$ del artículo $1^{\circ}$ de la Constitución establece obligaciones para el Estado que se derivan del hecho de que éste está al servicio de la persona humana:

"El Estado está al servicio de la persona humana y su finalidad es promover el bien común, para lo cual debe contribuir a crear las condiciones sociales que permitan a todos y a cada uno de los integrantes de la comunidad nacional su mayor realización espiritual y material posible, con pleno respeto a los derechos y garantías que esta Constitución establece." (el destacado es mío).

Por otra parte, el inciso $5^{\circ}$ dispone que el Estado debe

“(...) asegurar el derecho de las personas a participar con igualdad de oportunidades en la vida nacional."

Por otra parte, el inciso $2^{\circ}$ del artículo $5^{\circ}$ de la Constitución señala que:

"El ejercicio de la soberanía reconoce como limitación el respeto a los derechos esenciales que emanan de la naturaleza humana. Es deber de los órganos del Estado respetar y promover tales derechos, garantizados por esta Constitución, así como por los tratados internacionales ratificados por Chile y que se encuentren vigentes."

De la combinación de estas disposiciones, es posible concluir que estamos en presencia de un Estado Social, y en tal virtud hay una serie de acciones que aquél debe adoptar

Considerando $29^{\circ}$.

Ibid. 
para cumplir con tal carácter. Dentro de estas obligaciones relacionadas con el "crear las condiciones sociales que permitan a todos y cada uno de los integrantes de la comunidad nacional su mayor realización espiritual y material posible”, claramente se encuentra la de contar con un medio ambiente adecuado.

En virtud de aquel mandato que tiene constitucionalmente el Estado se desarrollan las acciones a través de las cuales éste satisface los derechos sociales. Para efectos del presente trabajo nos centraremos en el análisis del derecho a vivir en un medio ambiente libre de contaminación, garantizado en nuestra Constitución en el artículo 19 No 8, que dispone:

"La Constitución asegura a todas las personas: El derecho a vivir en un medio ambiente libre de contaminación. Es deber del Estado velar para que este derecho no sea afectado y tutelar la preservación de la naturaleza.

La ley podrá establecer restricciones específicas al ejercicio de determinados derechos o libertades para proteger el medio ambiente;"15

Ahora bien, tal como está regulado este derecho en nuestra Constitución, cabe preguntarse si es posible argumentar que se está en presencia de un derecho social o no. Un argumento que se puede dar a favor de la definición del DVMLC y la protección del medio ambiente en general como derecho social, radica en que para su adecuada satisfacción es indispensable que el Estado realice determinadas acciones, ya que no estamos en presencia de un derecho que se satisfaga con la mera inacción y no afectación del derecho por parte del Estado. En este sentido, la obligación de aquél “(...) consistiría, no ya en velar para que el derecho no se vea afectado, no ya en una declaración de reforzamiento del ámbito de la garantía de un derecho ya existente, sino en remover los obstáculos materiales o económicos que impiden a las personas concretar el ejercicio y goce de un derecho de este tipo. Ese sería el caso en que el Estado otorgara subsidios a las empresas y particulares para que puedan invertir en tecnología limpia o un plan de forestación financiado por el Estado, para que se pueda gozar de un mejor aire en la ciudad, o en un plan de pavimentación de calles de tierra -importante causa de contaminación en las ciudades de países subdesarrollados- de un sector de la ciudad." 16

Lo que sí está claro es la circunstancia de que la protección del medio ambiente paulatinamente ha ido ocupando un lugar central en el constitucionalismo de la segunda mitad del siglo XX, transformándose en un tema que supera lo meramente jurídico, abarcando áreas como la ética y la política. Al respecto, se ha seńalado que en “(...) la protección del medio ambiente se mezclan constantemente los derechos fundamentales e intereses legítimos de los ciudadanos, con ciertas exigencias políticas o éticas, como 
lo sería esta preocupación por el devenir de los seres humanos que vendrán ${ }^{17 ”}$. En el caso chileno se ha llegado a sostener, idea con la que concuerdo, que "la CPR no es neutra en materia ambiental y sitúa a la protección del medio ambiente en un lugar de preeminencia frente a otros derechos y bienes jurídicos" ${ }^{\prime 18}$.

Una característica interesante, que hace reafirmar la idea prima facie de que nos encontramos en presencia de un verdadero derecho social respecto del DVMLC y la protección del medio ambiente en general, radica en la circunstancia de que este derecho, a diferencia de la regulación de las libertades denominadas "negativas", no está limitado por la ley. Por ejemplo, en el caso del artículo $19 \mathrm{~N}^{\circ} 21$ que establece el derecho a la libre iniciativa económica nuestra Constitución señala: "El derecho a desarrollar cualquiera actividad económica que no sea contraria a la moral, al orden público o a la seguridad nacional, respetando las normas legales que la regulen." (el destacado es mío). Otro caso es el derecho de propiedad, que en el No 24 del artículo 19 mandata al legislador de la siguiente manera "Solo la ley puede establecer el modo de adquirir la propiedad, de usar, gozar y disponer de ella, y las limitaciones y obligaciones que deriven de su función social. Esta comprende cuanto exijan los intereses generales de la Nación, la seguridad nacional, la utilidad y la salubridad públicas y la conservación del patrimonio ambiental."

El DVMLC y la protección constitucional del medio ambiente no admiten limitación legal en su diseño ${ }^{19}$, a diferencia de los derechos antes mencionados (típicos DCP): el inciso $2^{\circ}$ del No 8 del artículo 19 de la Constitución establece que "La ley podrá establecer restricciones específicas al ejercicio de determinados derechos o libertades para proteger el medio ambiente". A diferencia de los derechos individuales clásicos seńalados en el párrafo anterior, cuyo ejercicio reconoce las limitaciones que imponga la ley, en el caso de la protección del medio ambiente se da la situación inversa, ya que aquélla es fundamento de determinadas restricciones de derechos.

Nuestra jurisprudencia ha reconocido que la protección del medio ambiente es un valor superior y que por ende, requiere de una especial atención. La Corte Suprema, respecto a la protección de las especies forestales nativas, en particular la Araucaria, al razonar respecto de la procedencia de las limitaciones al derecho de propiedad que imponía el decreto no 43 de 1990 del Ministerio de Agricultura, señaló que: "Entre aquellos derechos o valores superiores que el constituyente ha querido proteger aun a costa de sacrificar intereses de los individuos, se encuentran, entre otros, los relativos a la conservación del patrimonio ambiental, idea que surge del inciso $2^{\circ}$ del artículo 19 $n^{\circ} 24$ y del no 8 cuando señala que la ley establece restricciones específicas al ejercicio de determinados derechos o libertades para proteger el medio ambiente" ${ }^{20}$. La Corte,

BORDALÍ, Andrés, Op. cit. pp. 132-133.

BERMÚDEZ, Jorge "Fundamentos de Derecho Ambiental". Ediciones Universitarias de Valparaíso, 2007 p. 110 .

BERMÚDEZ, Jorge. Op. cit. p. 108.

20 Revista de Derecho y Jurisprudencia y Gaceta de los Tribunales, tomo LXXXVII, año 1990, 2o parte, sección 5, Santiago, Editorial Jurídica de Chile, p. 122-128. 
podemos seńalar a partir de este fallo, sienta el criterio que el DVMLC, y en general la protección del medio ambiente es uno de aquellos valores superiores que son protegidos especialmente por el constituyente, aun por encima del derecho de propiedad y de los derechos individuales.

Por otra parte, es propio de los derechos sociales imponer al Estado determinadas obligaciones para su satisfacción. Es posible observar que los derechos sociales comparten formulas normativas similares para la asignación de obligaciones al Estado, ejemplo de ello es la similitud de las utilizadas en el DVMLC con la del derecho a la educación, cuando se señala en los incisos $2^{\circ}$ y $3^{\circ}$ del № 10 del artículo 19 que:

"Para el Estado es obligatorio promover la educación parvularia y garantizar el acceso gratuito y el financiamiento fiscal al segundo nivel de transición, sin que éste constituya requisito para el ingreso a la educación básica.

La educación básica y la educación media son obligatorias, debiendo el Estado financiar un sistema gratuito con tal objeto, destinado a asegurar el acceso a ellas de toda la población..."

En el caso del derecho a la salud se señala en los incisos $2^{\circ}, 3^{\circ}$ y $4^{\circ}$ del No 9 del artículo 19 de la Constitución:

"El Estado protege el libre e igualitario acceso a las acciones de promoción, protección y recuperación de la salud y de rehabilitación del individuo ${ }^{21}$.

Como podemos observar, estos derechos comparten fórmulas normativas en tanto derechos sociales que requieren una actividad concreta del Estado para su satisfacción.

En las siguientes líneas argumentaré que en el caso del DVMLC y la protección del medio ambiente en general, sí nos encontramos en presencia de un derecho social, puesto que tiene una estructura compleja en la cual podemos encontrar las principales características que nos permiten calificar determinado derecho como social, a saber: derecho de carácter colectivo; fundamento en el principio de solidaridad; conexión con el principio de igualdad, en este caso con la igualdad intergeneracional; y consagración constitucional de obligaciones concretas para el Estado en orden a adoptar medidas para su resguardo.

21 Continúa señalando la disposición constitucional "Le corresponderá, asimismo, la coordinación y control de las acciones relacionadas con la salud.

Es deber preferente del Estado garantizar la ejecución de las acciones de salud, sea que se presten a través de instituciones públicas o privadas, en la forma y condiciones que determine la ley, la que podrá establecer cotizaciones obligatorias." 


\section{El carácter colectivo del Derecho Social a Vivir en un Medio ambiente Libre de Contaminación ${ }^{22}$}

El Derecho a vivir en un medio ambiente libre de contaminación es un derecho de carácter colectivo, es decir, sus titulares somos todas las personas. No es necesario que una persona específica sea la afectada para que se pueda solicitar su protección. Asimismo, es un derecho colectivo ya que se trata de un derecho sobre un bien colectivo (la mantención de un medio ambiente libre de contaminación), que representa los intereses agregados o acumulados de varias personas (aquellos miembros de la sociedad para los cuales esta característica es beneficiosa).

En este sentido, concuerdo con el profesor Cubillos cuando señala que las normas de la Constitución, y en particular aquéllas que se consagran para la protección del medio ambiente deban ser interpretadas con un sentido finalista ${ }^{23}$. Así aparece claro que el fin de la protección del medio ambiente no es de naturaleza puramente individual, sino que tiene un importante carácter colectivo. Por lo mismo, se ha señalado que "la problemática ambiental y ecológica constituye ahora la última frontera del Derecho Público por cuanto su naturaleza patrimonial, en la cual se inserta y asienta a la vez la familia humana, se concibe cada vez más como el bien común por excelencia”24.

Estamos en presencia de un derecho colectivo cuando el objeto de protección afecta a un determinado colectivo de personas, siendo cualquiera de las afectadas titular del derecho a nombre de las otras. Al respecto, Andrés Bordalí sostiene que sí se puede considerar a grupos de personas como titulares del DVMLC, en el entendido que "[p]or personas naturales puede pensarse en sujetos aislados o agrupados. En este caso, se puede decir, la organización colectiva o grupo representa una titularidad derivada de la que corresponde a las personas individuales. Estos grupos serían titulares del derecho fundamental porque a través de ellos se ejercen y expresan los derechos" 25 . Concretamente, a mi juicio, y de acuerdo con lo que he expuesto, la principal manifestación de lo colectivo radica en que las personas pueden exigir al Estado, tanto para sí como para el resto de los habitantes, la protección del medio ambiente, tanto respecto de la no contaminación como de la afectación o destrucción de la naturaleza.

22 Sin perjuicio del establecimiento del carácter colectivo del derecho a vivir en un medio ambiente libre de contaminación, nuestra jurisprudencia, a mi juicio erróneamente, ha limitado en numerosas ocasiones la legitimidad activa de recurrentes de protección por no considerarlos directamente afectados. Un ejemplo es el caso denominado "Albornoz c/Sociedad Maderera Aysén" (CS 19 enero 1993) en el que se sostiene que “(...) el derecho a recurrir de protección solamente lo tiene quien es directamente afectado por el hecho de acuerdo con el artículo 20 de la Constitución Política, calidad que no tienen los recurrentes quienes según sus propias declaraciones viven en San Bernardo y no podrían ser afectados con una eventual contaminación del medio ambiente en la Región de Aysén distante más de mil kilómetros de la Región Metropolitana”.

23 CUBILLOS, Gonzalo. "La extensión de la Garantía Constitucional referida al Derecho a Vivir en un Medio Ambiente Libre de Contaminación”. Gaceta Jurídica 2001, p. 264.

24 LÓPEZ, Alejandro. "El Derecho Fundamental al Medio Ambiente". Observatorio Medioambiental 1999, № 2, p. 15. Disponible en formato electrónico en http://revistas.ucm.es/cca/11391987/articulos/OBMD9999110013A.PDF [consulta: 10 Agosto 2009]

25 BORDALÍ, Andrés, Op. cit., p. 105. 
No obstante lo anterior, existen posiciones (con las que no estamos de acuerdo) que sostienen que, el medio ambiente en cuanto tal se considera un bien jurídico colectivo, lo cual no significa que constituya un "derecho colectivo", razón por la cual, para obtener su amparo por la vía del artículo $19 \mathrm{~N}^{\circ} 8 \mathrm{CPR}$ no basta esta titularidad genérica o erga omnes, sino que es necesario invocar el derecho subjetivo que efectivamente fue afectado. ${ }^{26}$

Más extrema y conservadora ha sido la doctrina nacional, puesto que considera que el DVMLC es un derecho derechamente individual y referido exclusiva y excluyentemente a una determinada persona, jamás a un colectivo. Resulta particularmente interesante confrontar las ideas que se plantean en esta sección con aquéllas que han sido desarrolladas por diversos autores que representan al sector más conservador y reaccionario de nuestra doctrina constitucional. Uno de sus representantes, Eduardo Soto, señala que "(...) no debe olvidarse jamás que son éstas -las personas- los verdaderos sujetos de la protección ecológica, desde que el ser humano, el señor de la creación, y para él es que fue creada por el Buen Dios" ${ }^{27}$. Soto va más allá, e incluso señala que el DVMLC es una emanación directa del derecho a la vida ${ }^{28}$, negando implícitamente su carácter autónomo. Esta posición es errónea en términos constitucionales, puesto que los derechos fundamentales interactúan entre sí, se relacionan, no se subordinan. Por lo mismo no es de extrańar que este autor tenga una mirada absolutamente restrictiva de este derecho, señalando que no es parte de su contenido la protección de la naturaleza ni la conservación del patrimonio ambiental, "licuando"de este modo uno de los aspectos esenciales de este derecho, el cual es la exigibilidad de las obligaciones que tiene el Estado en la materia.

Una postura muy similar a la expuesta anteriormente es la que plantea Enrique Evans, quien sostiene que la protección del medio ambiente está limitada, prima facie por los derechos individuales de las personas, lo contrario que hemos señalado en este trabajo, razón por la cual "será necesario (...) que una ley, como la prevista en el inciso segundo, que luego veremos, otorgue facultades al Poder Administrativo para adoptar medidas de cierta drasticidad (...)" ${ }^{29}$. Nosotros entendemos que el mandato constitucional no requiere de una medida legislativa para ser adoptado, ni tampoco consideramos que la autoridad requiera de facultades especiales para poder adoptar las medidas que correspondan para satisfacer el derecho colectivo al medio ambiente. Pero lo que está detrás de esta postura formalista de Evans, es el mismo discurso de Soto, en el sentido de limitar el DVMLC desconociendo su carácter colectivo y en general, desconociendo los componentes sociales que hoy en día son esenciales para comprender este derecho. Al igual que Soto, defenderá la característica de derecho individual del DVML señalando que: "[l]o importante es no confundir el derecho de

BERMÚDEZ, Jorge, op. cit. p. 75 .

SOTO, Eduardo, "El Derecho Fundamental a Vivir en un Ambiente Libre de Contaminación: su contenido esencial", en Gaceta Jurídica, № 151, año 1993, p. 22-23.

SOTO, Eduardo, op. cit. p. 24.

EVANS, Enrique, "Los Derechos Constitucionales". Editorial Jurídica de Chile, Santiago, 1986. p. 158. 
las personas a vivir en un medio no contaminado, para lo cual la tarea es eliminar o reducir los focos contaminantes existentes y preservar el equilibrio en la naturaleza para que el peligro no aparezca con otros caracteres o en otros sectores, con la custodia del paisaje, de la belleza turística, de la sobrevivencia de la flora y fauna o de otros valores del patrimonio nacional que, siendo muy importantes y dignos de protección en otros planos, no estén directamente comprometidos con la mantención de un ambiente digno del ser humano." 30

A diferencia de lo sostenido por la doctrina mayoritaria, en el caso del medio ambiente es particularmente clara la circunstancia de que nos encontramos frente a un derecho colectivo, puesto que su protección es del interés de todos los habitantes de un determinado espacio geográfico, ya que "tratándose de un derecho subjetivo a gozar de una determinada calidad ambiental, no se puede negar que se está frente a una situación que escapa de los tradicionales derechos subjetivos estrictamente individuales. En esta situación el fenómeno colectivo, además de manifestarse en el goce compartido y no exclusivo sobre el bien ambiente, viene a manifestarse especialmente al momento de solicitar la tutela jurisdiccional de este derecho" ${ }^{31}$.

Para justificar esta posición, Bordalí señala que existen dos formas a través de las cuales una persona puede relacionarse con el medio ambiente, una de ellas es el "ambiente inmediato" que sería aquella porción del medio ambiente que está siempre y a cada instante y lugar al alcance de la persona para satisfacer sus exigencias ambientales, la segunda de las formas es el medio ambiente remoto o mediato, el que "puede ser entendido como aquel espacio que si bien no está al alcance de un disfrute directo, es igualmente influyente y configurador del estado de propiedades de su ambiente inmediato futuro" ${ }^{32}$ Esta distinción es clave para comprender que la relación entre la persona y el medio ambiente es compleja y tiene componentes individuales y sociales que son imposibles de separar, por lo mismo, impiden que el DVMLC sea considerado como derecho fundamental meramente individual.

En términos de la titularidad del derecho, este tema es quizá el aspecto más polémico de la dimensión social que ha sido expuesta en el presente trabajo. Sobre este punto señalaré que considero que la titularidad de este derecho no está reservada a una determinada persona sino que puede ser alegado por un colectivo de personas, que es el rasgo distintivo de los derechos colectivos. Esta posición ha sido refrendada por una sentencia de la Corte Suprema, recaída en el recurso de protección "Horvath con CONAMA" el cual en su considerando $14^{\circ}$ reconoce respecto de la legitimación activa de los recurrentes (que había sido cuestionada por el recurrido) expresamente el carácter colectivo de este derecho: “(...) respecto de la supuesta falta de legitimación activa de los recurrentes para interponer este recurso, alegación efectuada por la recurrida y por la Forestal Trillium Ltda., cabe señalar que el derecho a vivir en un medio

EVANS, Enrique, op. cit. pp. 158-159.

BORDALÍ, Andrés, op. cit. p. 85.

BORDALÍ, Andrés, op. cit. p. 141. 
ambiente libre de contaminación es un derecho humano con rango constitucional, el que presenta un doble carácter: derecho subjetivo público y derecho colectivo público $(\ldots)^{\prime 33}$, el contenido de la dimensión colectiva del DVMLC, para la Corte, se conecta precisamente con el núcleo del presente trabajo, es decir en la naturaleza social de este derecho. "Y, en lo que dice relación con el segundo carácter del derecho en análisis, es decir, el derecho colectivo público, él está destinado a proteger y amparar derechos sociales de tipo colectivo, cuyo resguardo interesa a la comunidad toda, tanto en el plano local como en el nivel nacional" 34 .

Por otra parte, este derecho, y en general la protección constitucional del medio ambiente, es un antecedente para el ejercicio de los demás derechos de las personas, puesto que si no contamos con las condiciones ambientales adecuadas, el ejercicio de los demás derechos sería una quimera. Es más, el normal desarrollo de la vida como hoy la conocemos está en serio peligro si la afectación del medio ambiente se sigue produciendo en los términos que hoy se produce. Por ello se ha señalado que "(...) de continuar degradándose el medio ambiente al paso que vamos en la actualidad, llegará un momento en que su mantenimiento constituirá la más elemental cuestión de supervivencia en cualquier lugar y para todo el mundo"35. La Corte también en el fallo Horvath con CONAMA reconoce que el DVMLC es fundamental para el desarrollo de la vida, puesto que al no contar con condiciones ambientales adecuadas "se comprometen las bases de la existencia como sociedad y nación" 36 .

Otro aspecto en el cual es posible fundamentar la naturaleza de derecho colectivo del DVMLC radica en que en su regulación legal se reconoce el carácter colectivo al establecer instancias de participación a través de las cuales se reconoce el derecho de todas las personas a ser parte de las regulaciones ambientales ${ }^{37}$ a través de la obligatoriedad de incluir procesos de participación ciudadana en procesos ambientales clave: los Estudios de Impacto Ambiental y la dictación de normas de emisión y calidad ${ }^{38}$.

Otro rasgo que confirma que el Legislador considera a este derecho como un derecho social es la circunstancia de entregarle, especialmente, al Consejo de Defensa del Estado y las Municipalidades la titularidad de la acción para reclamar la reparación del daño ambiental. Esta es una alteración de las reglas clásicas de responsabilidad, en virtud de la cual solo el afectado por un determinado hecho puede solicitar la reparación del daño causado; en este caso, como estamos ante un caso de protección de un derecho

\footnotetext{
Ibíd. supra nota 29. El destacado es nuestro.

Ibíd. El destacado es nuestro.

LÓPEZ, Alejandro, op. cit. p. 16.

Ibid, supra nota 33 .

Vernet considera que una de las principales manifestaciones del carácter colectivo de este derecho social está en la "legitimación procesal para instar el control de las decisiones de los poderes públicos, en relación con el medio ambiente; así como la participación pública en la toma de dichas decisiones” VERNET, Jaime y JARIA, Jordi, "El Derecho a un Medio Ambiente Sano: su Reconocimiento en el Constitucionalismo Comparado y en el Derecho Internacional", en Teoría y Realidad Constitucional No 2, 2007, p. 519.

38 Se está estudiando en el Congreso una reforma a la ley 19.300 en virtud de la cual se permite la participación ciudadana en las Declaraciones de Impacto Ambiental ("DIA")
} 
colectivo, es la organización colectiva por excelencia, el Estado, a quien le corresponde la titularidad de esta acción ${ }^{39}$.

La preocupación por el medio ambiente despliega su dimensión colectiva no solo a nivel nacional, sino que principalmente a nivel internacional a través de su reconocimiento en diversos instrumentos internacionales, en los cuales ya sea directa o indirectamente se reconoce este derecho. Por lo mismo, la protección de este derecho exige un compromiso a nivel global, debido, además a la naturaleza supraestatal de los daños ambientales, "lo que implica un esfuerzo de protección planetaria del entorno y de la humanidad que en éste se desarrolla, por lo que la óptica tradicional según la cual se necesita acreditar una lesión individual no sirve a los efectos de proteger intereses colectivos como los que el medio ambiente reúne" ${ }^{\prime 4}$.

Ejemplo de esta protección internacional es la consagración que ha tenido en diversos instrumentos internacionales que, de acuerdo a lo dispuesto en el artículo $5^{\circ}$ inciso $2^{\circ}$ de nuestra Constitución constituyen un límite a la soberanía del Estado y son plenamente exigibles en nuestro ordenamiento interno; el más importante de ellos, el Pacto Internacional de Derechos Económicos, Sociales y Culturales, establece en su artículo 12:

"1. Los Estados Partes en el presente Pacto reconocen el derecho de toda persona al disfrute del más alto nivel posible de salud física y mental.

2. Entre las medidas que deberán adoptar los Estados Partes en el Pacto a fin de asegurar la plena efectividad de este derecho, figurarán las necesarias para:

b) El mejoramiento en todos sus aspectos de la higiene del trabajo y del medio ambiente;"

Otro instrumento que garantiza, pero de manera indirecta, este derecho, es la Declaración Universal de Derechos Humanos que señala, en su artículo 25, que:

"Toda persona tiene derecho a un nivel de vida adecuado que le asegure, así como a su familia, la salud y el bienestar, y en especial la alimentación, el vestido, la vivienda, la asistencia médica y los servicios sociales necesarios".

Otros instrumentos que, sin tener la categoría de tratados internacionales, son igualmente obligatorios para el Estado en términos de su responsabilidad internacional también reconocen el derecho fundamental a gozar de un medio ambiente adecuado; entre estos instrumentos internacionales podemos señalar:

39 CfrSPAGNA, Enrico, "La tutela constitucional de los intereses colectivos en el Estado de Democracia pluralista", en Revista de Estudios Políticos, No 4, 1998. Disponible en formato electrónico en

http://www.cepc.es/rap/Publicaciones/Revistas/3/REPNE_004_057.pdf [consulta: 10 Agosto 2009]

40 VERNET, Jaime y JARIA, Jordi, op. cit. p. 516. 
La Convención Americana de Derechos Humanos, que en su protocolo adicional en materia de $\mathrm{DESC}^{41}$ establece en el artículo 11:

"1. Toda persona tiene derecho a vivir en un medio ambiente sano y a contar con servicios públicos básicos.

2. Los Estados partes promoverán la protección, preservación y mejoramiento del medio ambiente."

En los últimos años, el reconocimiento del derecho a vivir en un medio ambiente libre de contaminación ha sido una de las principales herramientas para la protección del medio ambiente. La unión entre los derechos humanos y el medio ambiente se deriva del hecho de que la salud humana y la existencia misma, protegidas legalmente por el derecho a la salud y el derecho a la vida, dependen de las condiciones del medio ambiente $^{42}$.

\section{IV.- El fundamento en la idea de Solidaridad en el Derecho Social a Vivir en un Medio ambiente Libre de Contaminación}

El derecho al medio ambiente se funda en la idea de solidaridad, y ésta consiste en "el reconocimiento de la realidad del otro y la consideración de sus problemas como no ajenos, sino susceptibles de resolución con intervención de los poderes públicos y de los demás". ${ }^{43}$ Esta dimensión del medio ambiente se funda en la idea de que la obligación de respetarlo y protegerlo no se radica solo en el Estado, sino que nos abarca a todos, y por otro lado en función de su protección, se justifica la restricción de otros derechos (sin perjuicio de las disposiciones constitucionales expresas en esa materia).

Detrás de la idea de la solidaridad como fundamento de los derechos fundamentales en general, y de los derechos sociales en particular, hay un trasfondo político profundo, pues una sociedad democrática debe proteger el desarrollo de todas las personas, lo cual implica en determinadas ocasiones postergar los beneficios individuales en pos de los colectivos, y esta circunstancia muchas veces se observa en la tensión que se produce entre la protección del medio ambiente y el ejercicio de derechos individuales como la propiedad o la libre iniciativa económica. En este sentido, Peces-Barba señala que la solidaridad como fundamento de los derechos fundamentales tiene un objetivo político que consiste en "(...) la creación de una sociedad en la que todos se consideren miembros de la misma, y resuelvan en su seno las necesidades básicas, en la que no haya saltos cualitativos en los grupos en los que los hombres desarrollan

Al día de hoy, este protocolo adicional aún no es ratificado por Chile.

KISS, Alexandre y otro "Manual of European Environmental Law". Second Edition, Grotius Publications, Cambridge University Press, Cambridge, 1997, p. 85.

43 PECES-BARBA, Gregorio. "Curso de Derechos Fundamentales. Teoría General". Madrid, Coedición de la Universidad Carlos III de Madrid y Boletín Oficial del Estado, Madrid, 1999, pp. 279-280. 
su vida y actividad, en definitiva, en la que todos puedan realizar su vocación moral como seres autónomos y libres" ${ }^{4}$.

En lo que respecta a la protección del medio ambiente y su consideración como derecho social, se ha señalado en general que si el fundamento de los denominados derechos individuales era la libertad, el fundamento de los derechos sociales es la solidaridad, "por ello van íntimamente ligados deberes correlativos atribuidos a los propios titulares del derecho. La solidaridad como fundamento se explica por el carácter expansivo del bien jurídico protegido que constituye el contenido del derecho, ya que no se trata de la libertad de cada cual (...) sino de un objeto de carácter global que se proyecta hacia todos los seres humanos" $\$$.

Es esta proyección hacia todos los seres humanos el rasgo distintivo del DVMLC y que justifica su tratamiento como derecho social, lo que se traduce en la adopción de medidas y regulaciones que van más allá de la simple protección de intereses individuales.

En concreto, el carácter de solidaridad de este derecho tiene diversas manifestaciones o proyecciones, siendo la principal circunstancia de que cuando una persona interpone alguna de las acciones jurisdiccionales (constitucionales o de rango legal) relacionadas con la protección del medio ambiente, las consecuencias de dicha acción normalmente beneficiarán no solo a quien interpuso el recurso, sino que también al resto de la comunidad. Al respecto, se ha señalado que "cuando una persona solicita la cesación de una contaminación del ambiente, el resultado del ejercicio de dicha pretensión, si es acogida, beneficia al resto de los individuos que también se verían perjudicados con dicha contaminación, y esta situación no se da con el resto de los derechos subjetivos exclusivos y excluyentes. Es en esa particularidad donde radica la consideración de este derecho subjetivo como un interés colectivo." 46

En términos concretos, el fundamento solidario se manifiesta en que este derecho constituye un límite al ejercicio de otros derechos fundamentales; al respecto se sostiene que "(...) la tutela de los intereses generales es realizada básicamente a través de la imposición de límites al ejercicio de los derechos públicos subjetivos p cpm e; reconocimiento de algunos deberes fundamentales, como el respeto de la Constitución y de las leyes del Estado (... " ${ }^{47}$. En el caso de nuestra Constitución, es el caso del derecho a la libre iniciativa en materia económica (garantizado en el artículo 19 No 21), o bien el derecho de propiedad (garantizado en el artículo 19 № 24), dos derechos considerados tradicionalmente como individuales, y considerados por muchos como el fundamento de la sociedad moderna, los que se encuentran limitados por intereses generales, como es la protección del medio ambiente y la conservación del patrimonio ambiental.

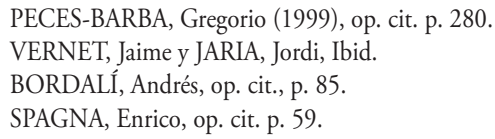


Los derechos antes mencionados ceden a favor de la protección del medio ambiente, debiendo tener en cuenta que "(...) la preservación del entorno físico del ser humano en unas condiciones que permitan no solo la existencia, sino también el bienestar, de acuerdo con los postulados del constitucionalismo existencial que deriva del Estado social, colisiona con otras aspiraciones del propio Estado social, como es el desarrollo económico" ${ }^{48}$; de esta forma se establecen límites expresos a la propiedad cuando se señala en el inciso segundo del artículo 19 № 24 que:

"Solo la ley puede establecer el modo de adquirir la propiedad, de usar, gozar y disponer de ella y las limitaciones y obligaciones que deriven de su función social. Esta comprende cuanto exijan los intereses generales de la Nación, la seguridad nacional, la utilidad y la salubridad públicas y la conservación del patrimonio ambiental." (el destacado es mío).

En virtud de las consideraciones anteriores, no es posible sostener que la protección del DVMLC se limite solo a la protección de intereses individuales, sino que resulta claro que "[s]i lo que la Constitución en definitiva protege es el derecho del hombre a un desarrollo sustentable, necesariamente debe entenderse que la garantía constitucional comprende la conservación de recursos naturales." ${ }^{49}$

En este sentido, un componente clave de la solidaridad en materia de protección del medio ambiente radica en que no es posible sostener que cualquier individuo tenga derecho al aprovechamiento ilimitado de los recursos naturales, sino que debemos ocuparlos de una manera que permita que otros también puedan hacerlo, e incluso permitiendo que las generaciones futuras, a su vez también lo hagan, correspondiendo al Estado, y en general a todas las personas, la obligación de ocuparse de la preservación de la naturaleza.

Otra de las manifestaciones de la solidaridad del DVMLC y de la protección del medio ambiente en cuanto derecho social, radica en el concepto de desarrollo sustentable, concepto recogido por la Ley 19.300 de Bases Generales del Medio Ambiente, en adelante la "ley 19.300" y que lo define como "el proceso de mejoramiento sostenido y equitativo de la calidad de vida de las personas fundado en medidas apropiadas de conservación y protección del medio ambiente, de manera de no comprometer las

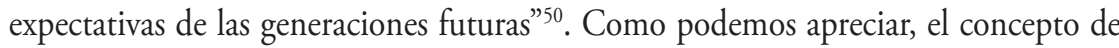
desarrollo sustentable tiene una doble dimensión, por un lado el componente equitativo entre el crecimiento económico y la protección ambiental, y por otro la noción de protección de las generaciones futuras, aspecto que se trata en el siguiente acápite de este trabajo. En dicha sección desarrollaré de manera más específica el concepto de desarrollo sustentable como dimensión relevante para el DVMLC como derecho social.

\footnotetext{
VERNET, Jaime y JARIA, Jordi, op. cit. p. 519.

CUBILLOS, Gonzalo. Ibid supra nota 23.

Letra g) del artículo $2^{\circ}$ de la ley 19.300.
} 


\section{V.- La conexión con el principio de igualdad, en particular la igualdad o equidad intergeneracional en el Derecho Social a Vivir en un Medio ambiente Libre de Contaminación}

Quizá el rasgo más interesante de la consagración del DVMLC como un derecho social sea el carácter intergeneracional que tiene su protección. En particular, el principio de igualdad o equidad intergeneracional es un principio de igualdad, consistente en que las presentes generaciones no deben dejar a las futuras en peor situación por las elecciones que se toman hoy en día.

La igualdad intergeneracional requiere, entonces, que se considere el impacto de nuestras actividades sobre las generaciones futuras, de este modo "(...) lo que se pretende es preservar para las generaciones futuras las condiciones para su propia supervivencia..." 51 Para implementar este principio, se requiere como mínimo utilizar sustentablemente los recursos y evitar el daño irreparable al medio ambiente; gran parte de esta forma de protección se plantea normativamente bajo fórmulas como la conservación del patrimonio ambiental y tutelar la preservación de la naturaleza.

La conexión con la idea de igualdad o equidad intergeneracional ha sido reconocida en el fallo "Horvath con CONAMA”, cuyo considerando 14 señala que: “(...) al dañarse o limitarse el medio ambiente y los recursos naturales, se limitan las posibilidades de vida y desarrollo no solo de las actuales generaciones sino también de las futuras. En este sentido, su resguardo interesa a la colectividad por afectar a una pluralidad de sujetos que se encuentran en una misma situación de hecho, y cuya lesión, pese a ser portadora de un gran daño social, no les causa un dańo significativo o al menos claramente apreciable en su esfera individual." ${ }^{2}$

Sin perjuicio de lo señalado, en la doctrina nacional Bordalí sostiene que este carácter intergeneracional es discutible, puesto que los derechos fundamentales se ejercen por las personas que actualmente gozan de existencia legal; en consecuencia, no pueden ejercer este derecho las personas que en el futuro gozarán de dicha existencia. No obstante aquello, señala que "tampoco se puede negar que con la protección del bienestar de ciudadanos actuales se logra indirectamente una protección intergeneracional del medio ambiente" 53 .

Uno de los aspectos clave de la dimensión intergeneracional del DVMLC es su conexión con la idea de desarrollo sustentable, a cuyo reconocimiento expreso en la ley 19.300 ya nos hemos referido anteriormente ${ }^{54}$. En términos conceptuales, podemos

\footnotetext{
VERNET, Jaime y JARIA, Jordi, op. cit. p. 521.

Ibid., supra nota 29.

BORDALÍ, Andrés, op. cit. p. 106.

Vid supra p. 13. Sin perjuicio del reconocimiento a nivel legislativo, es posible encontrar posiciones que consideran dudoso que este objetivo pueda cumplirse, al respecto Julio Lavín señala que "ni el reconocimiento hecho por las Constituciones, ni la existencia de una numerosa y completa legislación en materia ambiental, asegura per se la materialización del concepto de "desarrollo sustentable", el cual necesita para hacerse realidad, de un compromiso común tanto de los gobernantes como de los gobernados, el cual debe traducirse en la adopción de políticas, de
} 
señalar que desarrollo sustentable es aquel que satisface las necesidades del presente sin comprometer la capacidad de las generaciones futuras para satisfacer sus propias necesidades ${ }^{55}$.

El principio de la equidad intergeneracional, consiste en que las presentes generaciones no dejen a las futuras en peor situación a causa de las elecciones que se toman hoy en día. La equidad intergeneracional requiere, entonces, que se considere el impacto de nuestras actividades sobre las generaciones futuras. Para implementar este principio, se requiere como mínimo utilizar sustentablemente los recursos y evitar el daño irreparable al medio ambiente, así como ampliar el concepto de capacidad procesal a las generaciones futuras. ${ }^{56}$

\section{VI.- Las obligaciones que asume el Estado expresa y concretamente en la Constitución para efectos de la garantía del Derecho Social a Vivir en un Medio ambiente Libre de Contaminación.}

Se ha sostenido por parte de la doctrina nacional que el DVMLC tiene una doble dimensión, por un lado individual, que se manifiesta en el derecho que tiene cada persona por sí y para sí de exigir la protección del medio ambiente, dimensión que sería jurídicamente completa y permite argumentar que estamos en presencia de un derecho subjetivo concreto y exigible; y por otro lado una dimensión menos desarrollada, que tiene un carácter social o colectivo, y que dice relación con las obligaciones que al Estado le corresponden en lo relativo a la preservación de la naturaleza y la conservación del patrimonio ambiental, dimensión que no sería jurídicamente exigible, encontrándonos en presencia de disposiciones programáticas o aspiracionales.

Una posición particularmente ideologizada y recalcitrante es la que ha adoptado Raúl Bertelsen, quien sostiene que a diferencia de los derechos individuales, como la libertad personal o de expresión, que son derechos propiamente subjetivos, el medio ambiente no contaminado, en su dimensión colectiva, es una aspiración constitucional; "[e]n tal caso, lo que el constituyente busca es la realización de una serie de acciones positivas para prevenir o mejorar la calidad ambiental, y de ahí que deba fijar las bases para hacer posible y orientar su desarrollo. Tales bases, como hemos indicado anteriormente,

decisiones gubernamentales, de planes de acción, de fiscalización, así como de la colaboración, materializada en no pocas restricciones y renuncias voluntarias, de los gobernados en cuanto a la forma de ejercer sus derechos fundamentales y otros tantos esfuerzos comunes". LAVÍN, Julio "Legislación restrictiva de Derechos y Libertades para proteger el Medio Ambiente" en Revista Chilena de Derecho. Vol. 25 No 1, 1998, p. 177.

55 HUNTER, David et al. "International Environmental Law and Policy", New York, Foundation Press, 1998, p. 100.

56 Para un desarrollo del concepto de desarrollo sustentable ver ESPINOZA, Patricio y GARCÍA DE CORTÁZAR, Verónica. "El derecho a vivir en un medio ambiente libre de contaminación", extracto de "Medio ambiente y propiedad: una colisión inevitable". Memoria para optar al grado de Licenciado en Ciencias Jurídicas y Sociales. Profesor Guía Pablo Ruiz-Tagle Vial, Santiago, Universidad de Chile 2006. pp. 40-43. 
consistirán en la asignación de competencias, en la determinación de los objetivos a la acción estatal, y también en la precisión que efectúe en torno a las relaciones entre el derecho y el medio ambiente y otros derechos fundamentales" ${ }^{27}$.

Una posición más extrema es la de Eduardo Soto, quien señala que: "La preservación de la naturaleza, la protección o cuidado de los recursos naturales, el hábitat de los peces o las aves o los animales es un deber jurídico puesto a la carga del Estado de sus órganos que la ley cree al efecto [sic]; es una de las funciones del Estado, y es una de las competencias atribuidas por la ley (...) a determinados órganos estatales (v. gr. CONAF, etc.) pero ello no tiene nada que ver ni se encuentra incluido en el derecho fundamental, subjetivo, individual, que se le reconoce a cada persona por el constituyente para vivir en un ambiente libre de contaminación" 58 .

Las posturas señaladas precedentemente han sido expresamente dejadas de lado por la Corte Suprema al señalar que, "los recurrentes tienen derecho, además, a instar por la preservación de la naturaleza y la conservación del patrimonio ambiental, actividad que obviamente no solo compete a las personas que habitan cerca o en el lugar físico mismo en el que se estuviere desarrollando la explotación de recursos naturales y, desde ese aspecto, ellos también son afectados por la resolución recurrida;"59

A mi juicio, a diferencia de otros derechos, como el de propiedad, o la libertad personal, el DVMLC en nuestra Constitución comparte con los otros derechos sociales la circunstancia de imponerle al Estado una serie de obligaciones plenamente exigibles por las personas para satisfacerlo adecuadamente, siendo esta característica la que ha llevado a algunos autores a sostener que estamos en presencia de un derecho social ${ }^{60}$.

De acuerdo a lo anterior se ha señalado que "[e]n muchos de los llamados derechos fundamentales sociales, aparece un abanico de posiciones que reclaman en parte prestaciones fácticas, $y$ en parte, prestaciones normativas, sea a través de normas de protección, o de normas de organización y procedimiento" ${ }^{61}$. Por ejemplo, en el caso del DVMLC, el inciso primero del No 8 del artículo 19 de nuestra Constitución establece que:

"Es deber del Estado velar para que este derecho no sea afectado y tutelar la preservación de la naturaleza”.

57 BERTELSEN, Raul "El recurso de Protección y el Derecho a Vivir en un Medio Ambiente Libre de Contaminación. Examen de quince años de jurisprudencia. En Revista Chilena de Derecho. Vol. 25 No 1 pp. 141-142. SOTO, Eduardo. op. cit. p. 24.

59 Revista de Derecho y Jurisprudencia y Gaceta de los Tribunales, tomo XCIV, año 1997, 20 parte, sección 5º, Santiago, Editorial Jurídica de Chile, pp. 17-28.

60 BORDALÍ, Andrés, op. cit. p. 100. Agrega el autor que "[r] especto a la característica de derecho social que tendría el derecho a vivir en un medio ambiente libre de contaminación, tal característica se inferiría por la doctrina del propio artículo $19, \mathrm{n}^{\circ} 8 \mathrm{CPR}$, al establecer dicho precepto constitucional el deber del Estado de velar para que el derecho a vivir en un medio ambiente libre de contaminación no sea afectado y el deber estatal de tutelar la preservación de la naturaleza. Es decir, la faceta de derecho social se inferiría de un deber estatal”, p. 102.

61 GONZALEZ, Beatriz, op. cit., p. 144. 
Esta disposición impone al Estado dos obligaciones distintas, la primera de ellas es velar porque el derecho no se vea afectado, lo que se traduce en la adopción de medidas legislativas y de política destinadas a la prevención del medio ambiente, ejemplo de ello fue la dictación de la ley 19.300 y las regulaciones que de esta disposición se desprenden, como son las normas de calidad y de emisión, así como determinadas medidas de política como la restricción vehicular en determinados sectores del territorio.

Una segunda obligación que el artículo 19 No 8 impone al Estado es tutelar la preservación de la naturaleza, lo que se traduce en la creación de una institucionalidad especialmente destinada al efecto. Entre los órganos que se han creado es posible señalar a la Comisión Nacional del Medio Ambiente ${ }^{62}$, la Corporación Nacional Forestal, entre otras.

La obligación del Estado debe ser extendida a todos sus órganos en el área de sus respectivas competencias. ${ }^{63}$ Asimismo, el objeto de la protección es variado; de esta forma, que al Estado le corresponda velar que el derecho no sea afectado supone que éste no sea afectado de modo efectivo, "que no se produzca una privación o perturbación del mismo" ${ }^{64}$. Sin embargo, el deber del Estado, en materia de protección del medio ambiente, no se agota con la prevención de las acciones concretas, sino que también se extiende a las "situaciones omisivas y a las meras situaciones de riesgo y amenaza" ${ }^{65}$.

El Estado cumple con estas obligaciones, por ejemplo, a través de la dictación de normativa ambiental destinada a la prevención de situaciones contaminantes, caso de las normas de emisión que son definidas en la ley 19.300 como "aquélla que establece los valores de las concentraciones y períodos, máximos o mínimos permisibles de elementos, compuestos, sustancias, derivados químicos o biológicos, energías, radiaciones, vibraciones, ruidos o combinación de ellos, cuya presencia o carencia en el ambiente pueda constituir un riesgo para la vida o la salud de la población." 66

Por otra parte, la misma ley define que "preservación de la naturaleza", que es otra de las obligaciones constitucionales del Estado, es "el conjunto de políticas, planes, programas, normas y acciones, destinadas a asegurar la mantención de las condiciones que hacen posible la evolución y el desarrollo de las especies y de los ecosistemas del país" ${ }^{67}$. Asimismo, la ley define protección del medio ambiente como "el conjunto de políticas, planes, programas, normas y acciones destinados a mejorar el medio ambiente y a prevenir y controlar su deterioro." ${ }^{68}$

Algunos de los ejemplos a través de los cuales el Estado desarrolla esta obligación a través de medidas de política son los distintos programas que contempla la Ley de

62 Actualmente se discute en el Congreso la creación del Ministerio del Medio Ambiente, de la Superintendencia de fiscalización del Medio Ambiente y del Servicio de Evaluación Medioambiental.

BERMÚDEZ, Jorge, Op. citp 131.

BERMÚDEZ, Jorge, Op. cit., p. 132.

BERMÚDEZ, Jorge, Op. cit., p. 134.

Letra ń) artículo $2^{\circ}$ ley 19.300 .

Letra p) artículo $2^{\circ}$ ley 19.300 .

Letra q) artículo $2^{\circ}$ key 19.300 . 
Presupuestos de la nación relacionados con la protección del medio ambiente, entre los cuales se cuenta el Fondo de Protección Ambiental, con un total de 943.964 millones de $\operatorname{pesos}^{69}$ cuyo objetivo es "[f]inanciar, total o parcialmente proyectos o actividades orientadas a la protección o reparación del medio ambiente, la preservación de la naturaleza o la conservación del patrimonio ambiental"70. En total, para el año 2009, más de 4.700 millones de pesos se destinaron a programas relacionados con la protección del medio ambiente.

La relación entre ambos derechos puede ser vista de dos maneras. En primer lugar, la protección al medio ambiente puede ser vista como un medio para lograr el cumplimiento de los estándares de los derechos humanos. En segundo lugar, la protección de los derechos humanos puede ser vista como un medio efectivo para lograr los fines de conservación y protección del medio ambiente. Incluso hay quienes dicen que hay y debe haber un derecho humano inalienable a un medio ambiente satisfactorio, y que deben existir medios legales para hacer efectivo este derecho ${ }^{71}$.

\section{VII.- Conclusiones}

1. Los Derechos Sociales son derechos complejos, que se caracterizan por considerar diversos mecanismos de protección, entre los que se cuentan los recursos jurisdiccionales en virtud de las cuales las personas solicitan la protección de los mismos y el complejo entramado de obligaciones que el Estado asume para su adecuada satisfacción. Ambos tipos de vías de protección son igualmente efectivas y de directa invocación.

2. El DVMLC es un Derecho Social, pues comparte con aquéllos sus principales características: derecho colectivo, obligaciones especiales del Estado en la materia, fundamento en la idea de solidaridad y resguardo del principio de igualdad, en particular la noción de igualdad intergeneracional.

3. A pesar de que la doctrina nacional se ha esmerado en negar esta característica de derecho social al DVMLC, en fallos como Horvath con CONAMA, hemos visto que la Corte Suprema ha reconocido expresamente esta dimensión, la cual se ve reforzada por la regulación legal del derecho que, a través del reconocimiento explícito de instancias sociales por excelencia como la participación ciudadana y el establecimiento de acciones de titularidad del Estado (daño ambiental) refuerza la idea de que estamos ante un derecho social.

69 Ley 20.314 de Presupuestos del Sector Público para el año 2009 partida 22, capítulo 02 programa 01, subtítulo 24, Ítem 03/570.

70 http://www.conama.cl/rm/568/article-926.html

71 ESPINOZA LUCERO, PATRICIO; GARCÍA DE CORTÁZAR GALLEGUILLOS, VERÓNICA. "El derecho a vivir en un medio ambiente libre de contaminación", extracto de "Medio ambiente y propiedad: una colisión inevitable". Memoria para optar al grado de Licenciado en Ciencias Jurídicas y Sociales. Profesor Guía Pablo Ruiz-Tagle Vial, Santiago, Universidad de Chile 2006. p. 26. 
4. Pese a que recientemente se ha reconocido el carácter de derecho colectivo al DVMLC, aún persisten dudas razonables respecto de la titularidad de este derecho, teniendo presente que su principal medio de tutela, la acción de protección, se ha entendido en la jurisprudencia y la doctrina como una acción eminentemente individual, que para poder ser ejercida requiere que estemos en presencia de una persona directamente afectada.

5. El Estado está sometido a diversas obligaciones para la protección del medio ambiente, y las cumple a través de medidas legislativas, administrativas y de política. Esto demuestra que el derecho social a un medio ambiente adecuado goza de una posición preferente en nuestro ordenamiento. 